\title{
AN INVESTIGATION OF COMBINED COOLING EFFECTS ON GAS TURBINE BLADES
}

\author{
H. A. Abdalla M. Khalil Bassiouny T. I. Sabry \\ and Mostafa A. Abdel-Baky \\ Mechanical Power Engineering Department, \\ Faculty of Engineering, Minufiya University, \\ Shibin El-Kawm, Egypt.
}

\begin{abstract}
In this paper, experimental measurements of the cascade loss in addition to the local and overall cooling effectiveness on the suction and pressure surfaces of a gas turbine blade cascade are presented. The influence of the coolant ratio and inlet gases temperature on the cooling effectiveness are discussed. The experiments were performed with seven blades linear cascade of the first stage of a gas turbine. The experimental data were conducted for three cases; cold air, hot gas flow without cooling of the blade and hot gas flow with blade cooling. The combined cooling is achieved by a hole and five jets distributed at the leading edge. The experiments include the distributions of blade wall-to-gas temperature ratio and the velocity profiles measurements. The boundary layer parameters, cooling effectiveness and cascade loss were calculated. The influence of coolant temperature, inlet conditions of hot gases on the cooling effectiveness, the boundary layer growth and the cascade losses are investigated. The results indicated that, the cooling of the blade causes substantial increase in the boundary layer thickness and the secondary loss compared with that of uncooled blade. Also, the total loss increases as the flow moves in the direction of downstream and approaching the trailing edge. The comparison between the combined and internal cooling indicates that, the boundary layer thickness and the cooling effectiveness are higher in case of combined cooling which means more efficient in such applications.
\end{abstract}

\section{KEYWORDS}

Gas turbine, heat transfer, cooling effectiveness, cascade losses.

Manuscript received from ENG. MOSTAFA A. ABDEL- BAKY on : 15/12/1999 Accepted on : $5 / 2 / 2000$

Engineering Research Bulletin, Vol 23,No 2, 2000 Minufiya University, Faculty of Engineering, Shebien El-Kom , Egypt, ISSN 1110-1180 


\section{INTRODUCTION}

Among various types of turbomachinery, a lot of efforts have been made to increase turbine inlet gas temperature to achieve better engine cycle efficiency. On the other hand, the need to high inlet temperature is accompanied by cooling requirements for turbine components to protect it of damage. Therefore, highly sophisticated cooling techniques must be applied to maintain acceptable life and safety requirements for gas turbine components. Cooling of gas turbine components can be achieved by air or liquid. Liquid or water cooling, if possible, appears to be more attractive on account of the higher specific heat and possibility of evaporative cooling. However, the problems of leakage, corrosion, scale formation and choking militate against this method. Cooling by air, besides other advantages, allows it to be discharged into the main flow without much problems. It can be tapped out from the air compressor at a suitable point. Although the cooling of gas turbine blades aims to safe its life, it causes dramatic loss in the produced energy beside the aerodynamic loss. Many methods of cooling can be applied such as internal cooling, film cooling, impingement cooling or cooling by diffusion. In internal cooling, the coolant air flows in cooling passages or a hollow core. In film cooling, the coolant air is ejected from small holes to cover the blade surface with film layer which in turn prevent the blade surface from hot gases.

Initial investigations into the cooling of gas turbines were directed at determining the best method and effectiveness of cooling. The cooling effectiveness and aerothermal performance of film cooling depends on various flow parameters such as: density ratio, blowing or mass ratio and momentum flux ratio. However, film cooling offers a relatively simple technique for the efficient cooling of gas turbine blade walls. Hannis and Smith [1] measured the effect of cooling on the performance of gas turbines. The test results obtained by them for a first stage of gas turbine indicated an improvement in the performance of gas turbine with blade cooling. A comprehensive set of flow data for a single row of film cooling holes relevant to gas turbine application was acquired by Pietrzyk et al [2] with hole inclination angle of $35^{\circ}$. Their experiments were carried out on a flat plate in a wind tunnel. Previous workers on effusion cooling have demonstrated on the determination of the cooling effectiveness, Refs. [1-3], for few geometrical variables such as effusion hole confegeraion and inclination. An experimental investigation of full coverage film cooling on the pressure surface of a gas turbine blade is obtained by Kikkawa et al [4]. Coolant was injected from three holes on the center line of the pressure surface of a gas turbine blade. An empirical formula for the film cooling effectiveness on the centerline was presented as a function of the dimentionless streamwise distance from the ejection hole and the momentum ratio. Leading edge film cooling has been investigated by Kruse [5], Wadia and Nealy [6]. The former investigation was carried out with an airfoil representative of gas turbine blades and the later was carried out with a cylinder. Kruse found that the film effectiveness is very sensitive to the ejection angle, film-to-mainstream density ratio, film-to-mainstream velocity ratio and the blowing ratio. The high blowing rate provided no improvement in the cooling effectiveness downstream of the blowing jet. The adiabatic film effectiveness is 
found to be very sensitive to the relative distance of the blade arc. Goldstein and Chen [7] measured the local film cooling effectiveness on a gas turbine blade with a row of discrete cooling jets using a mass transfer technique. The results indicated a significant region on the suction surface close to the end wall over which the film cooling jets are essentially swept from the surface due to the presence of a passage vortex. This region commences somewhere downstream of injection, near the location where the passage vortex reaches the suction surface. Above this region and away from the end wall, the film cooling jets are skewed changing the distribution of local effectiveness, but the average effectiveness is not greatly altered. Film cooling on the pressure surface does not significantly affected by the end wall. The influence of the number of holes per unit surface area was investigated by Andrews et al. [8]. The results indicated that, increasing the number of holes and increasing of the hole diameter were shown to increase the cooling effectiveness through improved film cooling. Recently, a numerical analysis were carried out by Ameri and Rigby [9] to predict the distribution of convective heat transfer coefficient as well as the distribution of cooling effectiveness on simulated film cooled turbine blade. The results obtained were compared with experimental data obtained by Kim and Metzger [10].

Principal aerodynamic losses occurring in the most of the turbomachines arise due to the growth of the boundary layer and its separation on the blade and passage surfaces. Others occur due to wasteful circulatory flows and the formation of shock waves. Non-uniform velocity profiles at the exit of the cascade lead to another type of loss referred to as the mixing loss. The aerodynamic losses occurring in a turbine blade cascade can be classified to: profile loss, shock loss, annulus loss, secondary loss, tip clearance loss and endwall loss. In many instances a separate category called trailing edge loss is included to account for losses due to blunt trailing edge, which causes flow separation and shockexpansion-wave interaction due to sharp corners. This loss could be appreciable in transonic and supersonic turbines. In many instances, it is difficult, if not impossible, to distinguish between various sources of losses. In any case, it is useful to evaluate the various sources of losses to estimate the engine performance and minimize the losses through improved design or flow control.

The effect of Mach number and endwall cooling on the secondary flow in a straight nozzle cascade was studied experimentally by Sieverding and Wilputte [11]. It was indicated that, for low coolant mass flow rate, the influence of cooling is limited to the near wall region. Moore and Ransmayr [12] studied the effect of leading-edge shape on the overall losses in a large-scale linear cascade of turbine blades. The leading edge shape was a cylinder and wedge. It is noted that, about 50 percent of the losses occurred downstream of the trailing edge. The most significant result was that the highest entropy fluxes downstream of the cascade occurred near mid-span in a high loss core and not near the end-walls. Moore and Adhye [13] studied experimentally the loss mechanism and the behavior of secondary flows downstream of a large-scale, linear turbine cascade. They concluded that, the secondary flow field at each measurement plane was found to be dominant by a single large passage vortex, which decayed in strength because 
of the mixing occurring in the flow. They also found that more than one-third of the loss occurs downstream of the trailing edge. The endwall total pressure losses downstream of a low speed turbine cascade were measured by Chen and Dixon [14] at several planes to determine the changes in secondary flow loss coefficients and the growth of the mixing loss with downstream distance. Yamamoto et al [15] studied the overall performance and internal flows of air-cooled turbine blade rows. The cooled air was injected from various locations of the blade surface. They concluded that, the cascade overall loss decreased when the air was injected along the mainstream and increased when the air was injected against the mainstream from some locations of the blade leading edge. Haller and Camus [16] measured the aerodynamic loss for a state of the art film cooled transonic turbine rotor blade in a two dimensional cascade. The temperature of the coolant was equal to the cascade inlet stagnation temperature. It is noticed that, the ejection downstream of the throat did not generate significantly higher losses, even at high blowing rates, compared to prethroat suction surface films. They also noticed that, the cooling efficiency penalty was insensitive to hole shape and also surprisingly unaffected by changing the coolant density at constant blowing rate.

This paper concerns a program of experimental work carried out to study the influence of combined (internal and film) cooling on the blade cooling effectiveness and cascade losses. The experimental studies were obtained on a cascade consists of seven stationary blades of a gas turbine. The effect of combined cooling as well as the effect of inlet conditions of the main flow on blade surface temperature distribution, cooling effectiveness and cascade losses are presented. In addition, the effect of coolant mass flow rate is also examined. The distributions of the velocity profiles in the boundary layer at the midspan and at different locations along the suction surface are measured. The boundary layer parameters along the blade surface are calculated from the measured velocity distributions. The results are compared with that for the blade internal cooling conducted by Abdalla, et al. [17].

\section{EXPERIMENTAL TECHNIQUES}

\subsection{Test Facility and Experimental Procedure}

The development of the present cooling test facility was described in details by Abdalla, et al. [17]. It consists, as shown in Fig. (1), of a combustion chamber (7), a convergent transition section (8), an instrumental inlet section (11) and an instrumental test section (12). The combustion chamber is a gas fired burner. The fuel was injected at the entry through an injector. Air enters the burner continuously from an air compressor and controlled by means of a valve. The air flow rate is measured by a calibrated orifice-meter and it is admitted partially to the burner at three sections. The inlet section (11) is a steel rectangular duct of 400 mm length and $227 \times 56 \mathrm{~mm}$ inlet cross section area. The inlet conditions were measured ahead the tested cascade at the inlet section. The test section (12) was a seven blades linear cascade, Fig. (2). The linear cascade was fixed at the end of the inlet section. The blades profile was chosen for the first stage of a stator gas 
turbine. The blades were made of stainless steel and manufactured with an electric wire, computerized, cutting machine at the Aircraft Engine Factory of the Arab Consultation for Manufacturing. The blades have arithmetic surface roughness $\left(R_{a}\right)$ of $1.47 \mu \mathrm{m}$. The cascade geometry is given in Table (1).

Table (1) Cascade geometry

\begin{tabular}{|c|c|}
\hline Blade chord $(C)$ & $51.46 \mathrm{~mm}$ \\
\hline Cascade axial chord $\left(C_{a x}\right)$ & $25.73 \mathrm{~mm}$ \\
\hline Cascade pitch / Chord & 0.726 \\
\hline Blade height / Chord & 1.088 \\
\hline Maximum blade thickness & $11.0 \mathrm{~mm}$ \\
\hline Stagger angle $(\gamma)$ & $30^{\circ}$ \\
\hline Blade inlet angle $\left(\beta_{1}\right)$ & $90^{\circ}$ \\
\hline Blade exit angle $\left(\beta_{2}\right)$ & $15^{\circ}$ \\
\hline
\end{tabular}

The experimental procedure involves measurements in the three cases, namely: cold air flow, hot gas flow without blade cooling and hot gas flow with blade cooling. The mainstream flow rate for all cases was 3.7 and $5.2 \mathrm{~kg} / \mathrm{min}$ and the coolant mass flow rates were taken to be $0.009,0.012,0.015 \mathrm{~kg} / \mathrm{min}$ for each case of gas flow rates. The total pressure and the gas temperature were measured in each case before and after the cascade, in addition to the blade surface temperature distributions. For each case of gas flow rate, the temperature at cascade inlet was kept constant at 473,493 and $513 \mathrm{~K}$ by controlling the fuel flow rate. Unfortunately, the test facility gives limited actual gas inlet temperatures compared to the actual values at inlet to the first stage of gas turbines. For conducting the system in the steady state, the required amount of mainstream was permitted to flow through the burner then the fuel was injected and the spark was ignited. The hot gas produced by combustion passed through a duct to the test section. The temperature was observed at the computer monitor until it reached steady state (usually in 10-15 minutes). Then all of the temperature readings were recorded at the same time for all points. Furthermore, the previous experimental tests were repeated for different inlet gas temperatures and different hot gas flow rates.

\section{2 Combined Cooling Arrangement}

For combined cooling process, a hole of $4 \mathrm{~mm}$ inner diameter was drilled in the direction parallel to the blade height for making the cooling air flow passage, as shown in Fig. (3-a). Five holes of $1 \mathrm{~mm}$ diameter and $10 \mathrm{~mm}$ interval are drilled perpendicular to the cooling passage at the blade leading edge. These holes will produce jets that penetrate a shorter distance into the boundary layer and hence will have a thinner thermal boundary layer and more effective film cooling. The film cooling boundary layer is influenced by the velocity of the coolant jets discharged into the cross flow and the associated pressure loss which governs the generated turbulence. The air required to the blade cooling is measured using two calibrated orifice meters installed before and after the cooled blade as shown in 
Fig. (3-b). A hot gas stream with different temperature was used with the air at the ambient temperature. The axial variation of the cooling effectiveness was based on four thermocouples along the pressure surface of the blade at the mid-span and six thermocouples along the suction surface. The thermocouples used are Nickel Chrome-Nickel Aluminum (type $\mathrm{K}$ ) and they were calibrated and installed in grooves of $1 \times 1 \mathrm{~mm}$ cross section and it was insulated with high temperature synthetic fibers. The thermocouples nodes were $0.5 \mathrm{~mm}$ diameter and placed at the mid-span of the blade. This set of thermocouples determined the axial variation in the cooling effectiveness due to the axial development of the combined cooling boundary layer. The cooling performance of gas turbine blades is expressed in the form of the cooling effectiveness ( $\varepsilon$ ), Ref. [18], as:

$$
\varepsilon=\frac{\mathbf{T}_{\mathrm{g}}-\mathbf{T}_{\mathbf{w}}}{\mathbf{T}_{\mathrm{g}}-\mathbf{T}_{\mathrm{c}}}
$$

Where $T_{g}$ is the gas temperature along the blade passage, $T_{w}$ is the wall temperature and $T_{c}$ is the coolant inlet temperature. The average cooling effectiveness $(\bar{\varepsilon})$ was calculated from the following equation:

$$
\bar{\varepsilon}=\frac{\mathbf{T}_{\mathrm{g}, \mathrm{m}}-\mathbf{T}_{\mathrm{w}, \mathrm{m}}}{\mathbf{T}_{\mathrm{g}, \mathrm{m}}-\mathbf{T}_{\mathrm{c}}}
$$

Where $T_{g, m}$ is the mean gas temperature between inlet and outlet of the cascade, $T_{w, m}$ is the wall mean temperature and $T_{c}$ is the coolant inlet temperature.

\section{3 Experimental Measurements and Uncertainty}

The main gas flow rate was measured before entering the burner. It was controlled by a valve and an orifice meter. The flow rate of coolant was measured and controlled with the aid of two orifice-meters installed before and after the cooled blade. The difference between the two measured values gives the film coolant flow rates. The first orifice diameter ratio was 0.7 and the second one was 0.5. The experimental error in measuring the mass flow rate of coolant air was 0.5 percent. The total pressure was measured before the cascade inlet with the aid of a calibrated total-static Pitot tube to establish the total and static pressure at the cascade inlet. The total pressure was measured with the aid of a three hole probe at $5 \mathrm{~mm}$ down stream of the cascade in the direction of the blade height. A water tubes manometer was used for measuring the pressure head. The experimental error in measuring the static pressure is about \pm 0.1 percent. The boundary layer velocity profiles were measured at four stations on the suction surface. The surface distance ratios $(S)$ of these stations were $0.464,0.549,0.628$ and 0.710 . The velocity profiles measurements were conducted for the cases of cold and hot gas flows with and without cooling. A flatted probe of $1.1 \times 0.4 \mathrm{~mm}$ outer dimensions was used for measuring the velocity profiles. It was found that the probe causes a blockage in the blade passage less than 5 percent. The experimental error in measuring the velocity is about \pm 0.5 percent. The inlet and outlet gas temperatures as well as the blade wall temperature were measured. The thermocouples were attached to a data acquisition system. The data acquisition system, model ( AT- 
MIO-16 ), is supplied with SCXI-1000 interface capable of connecting 32 channels. The accuracy of the data acquisition system is 0.01 percent. All of the temperature signals are acquired and sent to a personal computer for recording and plotting. The system permits temperature reading for all points at steady state and at the same time. The experimental error in measuring the temperature is about \pm 0.5 percent.

\section{EXPERIMENTAL RESULTS}

The following is a presentation and discussion of the effect of combined cooling on boundary layer growth, blade wall temperature distributions, cooling effectiveness and the cascade losses.

\section{1 Velocity Profiles Results}

The mean velocity profiles and boundary layer growth are affected by the blade wall temperature and blade cooling. To study this effect, the blade was heated by gas flow and then it was cooled at constant inlet gas temperature. Figure (4) represents the effect of heating and cooling on the velocity profiles on the suction surface at four stations along the flow passage. The inlet gas temperature and the inlet coolant temperature were kept at 473 and $293 \mathrm{~K}$, respectively. It is seen from this figure that the velocity values increase with heating comparing with that for cold air flow. The effect of cooling on the measured velocity profile at $S=$ 0.464 , Fig. (4-a), is remarkable to decrease the velocity values compared to that of uncooled blade surface. This means that, the boundary layer thickness is increased when the blade surface is cooled. Unfortunately, the difference in velocity values appears to be small due to the limited coolant mass flow ratio $\left(\dot{\mathbf{m}}_{\mathrm{c}} / \dot{\mathbf{m}}_{\mathrm{g}}\right)$. In addition, the effect of cooling on the velocity profiles is vanished near the trailing edge, Fig. (4-d). This is because the cross section area of the cooling passage is small and limited with the maximum blade thickness and the film layer achieves a low cooling effectiveness. This leads to that, the cooling becomes more effective if it is applied over the all blade surface.

The integral boundary layer parameters such as the displacement thickness $\left(\delta^{*}\right)$ and the shape factor $\left(\mathrm{H}=\delta^{*} / \theta\right)$ are calculated from the measured mean velocity profiles for the different cases. The displacement thickness was normalized by the boundary layer thickness $(\delta)$. Figure $(5)$ illustrates the effect of heating and cooling on the growth of the boundary layer parameters. For cold air flow case, the displacement thickness increases with increasing the arc distance ratio (S), Fig. (5- a). Correspondingly, the shape factor of the boundary layer increases with increasing the distance (S) as shown in Fig. (5-b). It is also noticed that, the values of the shape factor at about $S=0.7$ and near the trailing edge does not reach the separation criterion, which is taken as $1.8<\mathrm{H}<2.4$, Ref. [19]. In the case of heated blade without cooling, it is clearly shown that the displacement thickness as well as the shape factor have values smaller than those of cold air flow case. Therefore, the effect of blade cooling is understood to increase the 
boundary layer thickness compared with that of heated blade without cooling. To summarize, the blade cooling causes a destabilizing effect of the boundary layer development along the blade surface.

\section{2 Results of Wall-to-Gas Temperature Ratio}

The ratio of wall-to-gas temperature $\left(\mathrm{T}_{w} / \mathrm{T}_{\mathrm{g}}\right)$ of gas turbine stationary blades is influenced by many parameters such as inlet gas temperature, coolant mass flow rate and gas flow rate. Figure (6) illustrates the effect of cooling on the wall-to-gas temperature ratio for $5.2 \mathrm{~kg} / \mathrm{min}$ main flow rate at $513 \mathrm{~K}$ gas inlet temperature. The coolant temperature is kept constant at $293 \mathrm{~K}$ while the coolant flow ratio $\left(\dot{\mathbf{m}}_{\mathrm{c}} / \dot{\mathrm{m}}_{\mathrm{g}}\right)$ was taken off $1.73 \times 10^{-3}, 2.31 \times 10^{-3}$ and $2.88 \times 10^{-3}$. Thermal gradients are shown in this figure along the blade surface. It is clear that, the wall-

to-gas temperature ratio decreases when the coolant ratio $\left(\dot{\mathbf{m}}_{\mathrm{c}} / \dot{\mathbf{m}}_{\mathrm{g}}\right)$ is increased. The wall-to-gas temperature ratio $\left(\mathrm{T}_{w} / \mathrm{T}_{\mathrm{g}}\right)$ has its lower values near the leading edge indicating a better film cooling. As the film layer moves towards the trailing edge, it becomes a more thinner and so the blade wall temperature increases as indicated in Fig. (6).

\section{3 Axial Variation of Cooling Effectiveness}

The development of the cooling effectiveness with axial distance along the blade surfaces is shown in figures (7) for different coolant mass flow rates. In Figs. (7-a) and (7-b), the main hot gas flow rate was kept constant at $3.7 \mathrm{~kg} / \mathrm{min}$ while the inlet gas temperature was taken of $473 \mathrm{~K}$ and $513 \mathrm{~K}$ respectively. The results show that, the axial variation of the cooling effectiveness was thus mainly due to the development of the film cooling. It is indicated that, the cooling effectiveness has its higher value near the leading edge where the coolant air formed a protective film that insulate the blade wall from the hot gases. The blade cooling effectiveness decreases in direction of the trailing edge due to the poor film cooling that results in a low cooling effectiveness. Increasing the coolant mass flow rate leads to an increase of cooling effectiveness as shown in the figures due to the greater mass of cool air in the film and the increased jet velocities which increased the wall cooling. Comparison of Figs. (7-a) and (7-b) indicates clearly that, the cooling effectiveness decreases when the inlet gas temperature is increased. This is due to the increase of heat transferred from the hot gases to he blade wall. In Fig. (7-c), the hot gas flow rate was taken to be $5.2 \mathrm{~kg} / \mathrm{min}$ while its inlet temperature was kept constant at $473 \mathrm{~K}$. It is known that, the increase of main flow rate means an increase in the heat content. This will be reflected on the blade wall temperature which increases as the main flow rate increases. The axial variation of the cooling effectiveness was thus mainly due to the development of the film cooling and it was dominated by the wall heat transfer.

Figure (8) indicates the effect of the coolant mass flow ratio $\left(\dot{\mathbf{m}}_{\mathbf{c}} / \dot{\mathbf{m}}_{\mathrm{g}}\right)$ on the average cooling effectiveness $(\bar{\varepsilon})$ for mainstream flow rate of $3.7 \mathrm{~kg} / \mathrm{min}$. The 
coolant temperature was kept constant at $293 \mathrm{~K}$ while the inlet gas temperature was taken to be 473,493 and $513 \mathrm{~K}$. It is observed that the average cooling effectiveness increases with increasing the coolant mass flow ratio. This is referred to the accompanied decrease of the blade wall temperature with increasing the coolant mass flow rate which leads to an increase of the heat transfer between the coolant passage and the blade wall as the coolant accelerated into the cooling passage. Consequently, this decreases the blade wall temperature. It is seen also that the mean cooling effectiveness increases when the gas inlet temperature decreases.

\section{4. Aerodynamic Losses for Cold Air Flow}

The total aerodynamic losses through the tested cascade was measured for the case of the cold air flow $(T=293 \mathrm{~K})$, and illustrated in Fig. (9) for different exit Reynolds numbers. It appeared from the Figure that, the total aerodynamic loss $\left(\xi_{\mathrm{t}}\right)$ is decreased until about $\mathrm{y} / \mathrm{h}=0.072$, afterwards a slight increase in the aerodynamic losses is remarked up to $y / h=0.175$ and then it has a constant values. The observed peak in the aerodynamic loss is due to the circulatory flow near the cascade walls. However, the intensity of the circulatory flows appears to be small due to the low values of Reynolds number. It is observed also from Fig. (9) that, the total aerodynamic losses decreased with increasing the Reynolds number on account of increasing the level of turbulence which affects the boundary layer separation on the suction surface of the blade. The variation of secondary loss, profile loss and total loss with Reynolds number are presented in Fig. (10). The figure shows that the increase of secondary losses starts at the lowest Reynolds number. This is referred to the nature of secondary flow in the cascade passage which is given by Squire and Winter [20]and by Hawthorne [2122]. The secondary flow is generated by the turning effect of the curved passage as well as by the Horseshoe vortex phenomena, which results from the interaction of the end wall boundary layer flow with the blade leading edge. On the other hand, the secondary flow through the curved passage is regarded as perturbation on an essentially two-dimensional motion. Because of the turning of the stream, there is a pressure gradient across the blade passage to balance the centrifugal forces. Therefore, the main reasons of decreasing the secondary loss with increasing the Reynolds number is that, the radial velocity and the radial pressure gradient are decreased with increasing the Reynolds number. This, consequently, affects the strength of the pressure - driven secondary cells and the initial distribution of normal vorticity. As a result of this, the distribution of the axial velocity is increased and the boundary layer becomes thinner. Due to the previous mentioned reasons, the secondary losses will be increased with increasing the Reynolds number. Blade profile loss is considered as a portion of the total losses which would be measured by tests in the profile in the absence of any disturbance effects due to the presence of walls at blade extremities. The profile loss, generally, occurs due to the friction and boundary layer separation over the blade surfaces. Although profile losses can be related to physical blade properties such

as blade pitch, thickness and throat opening and to gas incidence, they can also be related more fundamentally to the form of the velocity and pressure distributions 
around the blade. The pressure distribution controls the nature of the boundary layers which form the blade wake. The effect of Reynolds number on the cascade profile loss is shown also in Fig. (10). It is observed clearly that, the profile losses are decreased with increasing the Reynolds number. The maximum profile losses occurs at the smallest tested Reynolds number, $\operatorname{Re}=3 \times 10^{4}$.

Figure (11) shows the total loss coefficient distribution along the flow path through and behind the cascade $\left(\mathrm{Z} / \mathrm{C}_{\mathrm{ax}}\right)$ for different exit Reynolds numbers. The results are plotted from $\mathrm{Z} / \mathrm{C}_{\mathrm{ax}}=0.897$ up to 1.388 to indicate the growth of the total loss in the region of the blade trailing edge and mixing zone downstream the tested cascade. A remarkable increase in the total loss as the flow moves in the downstream direction and approaching the trailing edge. A great increase in the total loss occurs in the region of the trailing edge which seems to be somewhat similar to sudden expansion loss. This occurs due to the presence of corner losses near to the exit plane, for Reynolds number $\operatorname{Re}=3.09 \times 10^{4}$. With increasing Reynolds number, this phenomenon tends to disappear at the exit plane. It is observed that, the end-wall cross flow and the blade wake merge in the trailing edge region in a manner quite similar to that observed by other investigators. This region is accompanied with high mixing losses like that occurs in a sudden expansion. Immediately downstream of the trailing edge of any blade, there is a surface discontinuity of velocity, equivalent to a vortex sheet. These vortex sheet is unstable and rolls up into trailing vortices. It is appeared also from Fig. (11) that the mixing zone extends about $38 \%$ of the blade axial chord downstream the cascade, in addition to a decrease in mixing losses with increasing the Reynolds number. After the mixing region, the losses are negligible with respect to those occurred inside the passage and the region immediately after the blades.

\section{5. Cascade Losses with Heat Transfer and Cooling}

The effect of increasing of the inlet gas temperature on the total loss across the tested cascade is shown in Fig. (12) for mass flow rate of $5.2 \mathrm{~kg} / \mathrm{min}$. The inlet gas temperatures are taken to be 473,493 and $513 \mathrm{~K}$. The total loss coefficient for cold air flow case is included also in these figures. The corresponding exit Reynolds number for cold air is 43700 and those for the hot gases are 41900 , 44000 and 45200 . Generally, the aerodynamic loss increases for heated flow than that for cold air case. The increase of gas temperature leads to an increase of the inlet and consequently exit Mach number. The profile loss increases also with increasing the gas stream temperature due to the increase of molecular viscosity which increases also the friction losses across the passage. Figure (13) represents the effect of blade cooling on the aerodynamic loss. The main flow rate is 5.2 $\mathrm{kg} / \mathrm{min}$ at $513 \mathrm{~K}$ while the coolant flow rate is $0.015 \mathrm{~kg} / \mathrm{min}$ at a temperature of $293 \mathrm{~K}$. The cold air flow and the hot gas without blade cooling are also represented in the figure. It is observed that the cooling has a very small effect on the aerodynamic loss within the tested conditions. The small effect of cooling is due to the small amount of coolant. This means that, the cooling could have a remarkable effect on the aerodynamic loss if it is applied to the whole blade surface. 


\section{6 Comparison Between combined and Internal Cooling}

Figures (14) to (17) are drawn to indicate the comparison between combined cooling and the internal cooling results presented in Ref.[17] at the same test conditions. In Fig. (14) the comparison between the effect of combined and internal cooling on the boundary layer development is indicated. It is shown that, the boundary layer parameters are increased in the case of combined cooling due to the presence of the film layer induced by the cooling jets. As a sequence of the increase in the boundary layer thickness, in the case of combined cooling, a remarkable decrease in the wall-to-gas temperature ratio is observed near the leading edge, as seen from Fig. (15), where the cooling jets are holed. The difference in the wall temperature ratio diminishes in direction of the trailing edge. The decrease in the wall temperature in the case of combined cooling is reflected on the distribution of blade cooling effectiveness, Fig. (16). This means that, an increase in blade cooling effectiveness is seen near the cooling holes. This gave an indication that the combined cooling is more useful than the internal cooling. Therefore, to have a better cooling effectiveness it is recommended to cover a large area of the blade by cooling holes. Figure (17) represents the effect of the cooling method on the mean cooling effectiveness of the blade. The comparison indicates that, the increase of cooling effectiveness is more steeply faster for combined cooling than the internal cooling. This can be explained as follows: the mean combined cooling effectiveness determines the combined influence of the film cooling and the internal wall cooling. Reducing the pressure loss across the jets improved the combined cooling effectiveness through a reduction in the film boundary layer. For fixed coolant mass flow rate into the jets, the jets pressure loss is proportional to the square of coolant mass flow rate. Therefor, the film cooling boundary layer influenced by the coolant mass flow rate or the velocity of the coolant jets discharging into the cross flow and by the associated pressure loss which governs the turbulence that is generated. Correspondingly, increasing the coolant mass flow rate tends to increases the thickness of the film boundary layer and hence the mean combined cooling effectiveness. This means that more coolant mass flow rate is required in the case of internal cooling than that required in the case of combined cooling to maintain the same wall temperature of the blade.

\section{CONCLUSIONS}

Experimental measurements of the cooling effectiveness and loss coefficients for combined cooling were made on gas turbine blade cascade. The main conclusions of the present experimental study are:

1- The cooling of the blade causes substantial increase in the boundary layer thickness compared with that of heated blade without cooling. This means that, the blade cooling causes a destabilizing effect of the boundary layer and consequently the secondary loss is increased.

2- The cooling effectiveness increases near the leading edge where the coolant air formed a protective film that insulate the blade wall. 
3- The total aerodynamic and profile losses decrease when the Reynolds number is increased while the secondary loss of the cascade is increased.

4- The total loss increases as the flow moves in the direction of downstream and approaching the trailing edge. The rate of increase of the total loss increases in the region of trailing edge which seems to be somewhat similar to sudden expansion loss. The mixing losses after the trailing edge represents a great portion of total loss (about 38 percent of the total loss).

5- The increase of the exit Reynolds number or inlet gas temperature results in a change of the pressure gradient across the blade passage causing an increase of the secondary and the profile losses.

6- The energy loss for the uncooled and cooled blade decreases with increasing the inlet gas temperature due to the accompanied increase in the Reynolds number.

7- The comparison between the combined and internal cooling indicates that, the boundary layer thickness and the cooling effectiveness are higher in the case of combined cooling than that of internal cooling. This means that the combined cooling of gas turbine blades is more efficient in such applications.

\section{NOMENCLATURE}
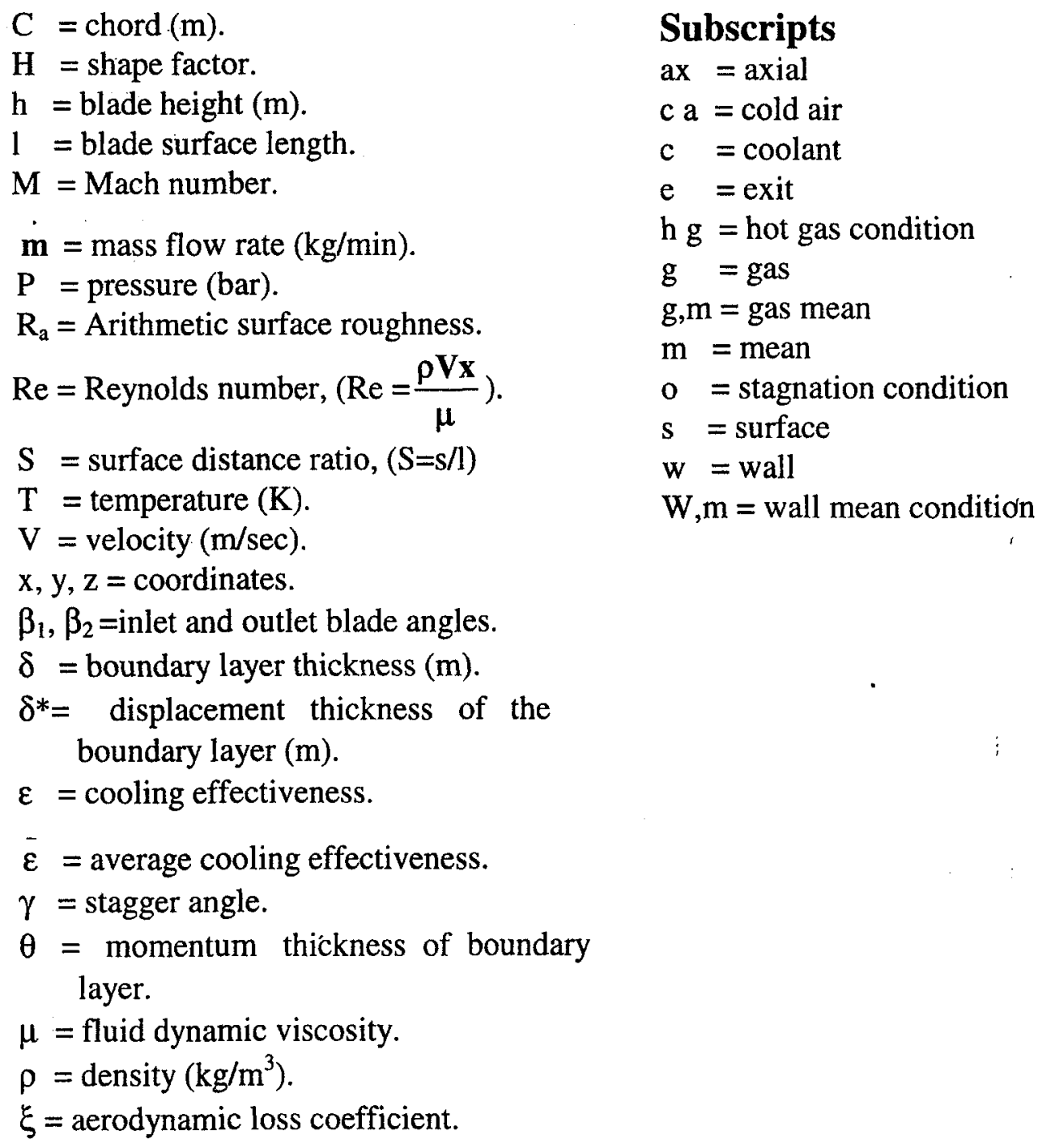


\section{REFERENCES}

1- Hannis, J. M. and Smith, M. K. D., "The Design and Testing of Air Cooled Blading for an Industrial Gas Turbine," TRANS. ASME J. Engineering for Power, Vol. 105, P. 466, 1983.

2- Pietrzyk, J. R., Bogard, D. G. and Crawford, M. E., "Effect of Density Ratio on the Hydrodynamics of Film Cooling." TRANS. ASME. J: of Turbomachinery, Vol. 112, P. 437, 1990.

3- Trushechkin, V. P., Kolotnikov, M. E., "Theoretical- Experimental Study of the Thermal Fatigue of Gas Turbine Blades." Strength of Materials (English translation of problem Prochnosti.) P. 223, 1988.

4- Kikkawa, Shinzo, Sakaguchi and Katsuji, "Experimental Investigation of Full Coverage Film Cooling on the Pressure Surface of a Gas Turbine Blade." Heat Transfer- Japanese research Vol. 19, P. 43, 1990.

5- Kruse, H. "Investigation of Temperature Distribution Near Film Cooled Airfoils," AGARD CP 229, 1977.

6- Wadia, A. R. and Nealy, D. A., "Development of Design Model for Airfoil Leading Edge Film Cooling," ASME Paper 85-GT-120, 1985.

7- Goldstein, R. J. and Chen, H. P., "Film Cooling on a Gas Turbine Blade Near the End Wall," Trans. of the ASME. J. of Engg. for Gas Turbines and Power, Vol. 107, P. 117, 1985.

8- Andrews, Asere, A. A. and Mkpadi, M. C., "Effusion Cooling: The Influence of the Number of Holes" Proc. Instn. Mech. Engrs. Vol. 204, P. 175, 1990.

9- Ameri, A. A. and Rigby, D. L., "A Numerical Analysis of Heat Transfer and Effectiveness on Film Cooled Turbine Blade Tip Models." NACA/ CR-1999209165

10- Kim, Y. W. and Metzger, D. E., "Heat Transfer and Effectiveness on Film cooled turbine Blade Tip." Journal of Turbomachinery, Vol. 117, p. 12, Jan. 1995.

11- Sieverding, C. H., Wilputte, Ph., "Influence of Mach Number and End Wall Cooling On Secondary Flows in a Straight Nozzle Cascade." TRANS. ASME. J. Engineering for Power, Vol. 103, P. 257, 1981.

12- Moore, J. and Ransmayr, A., "Flow in a Turbine Cascade: Part I- Losses and Leading-Edge Effects." TRANS. ASME. J. Engineering for Gas Turbine and Power, Vol. 106, P. 400, 1984.

13- Moore, J. and Adhye, R. Y., "Secondary Flow and Losses Downstream of a Turbine Cascade." TRANS. ASME. J. Engineering for Gas Turbine and Power, Vol. 107, P. 961, 1985.

14-Chen, L. D. and Dixon, S. L., "Growth of Secondary Flow Losses Downstream of a Turbine Blade Cascade." TRANS. ASME. J. Engineering for Gas Turbine and Power, Vol. 108,P. 270, 1986.

15- Yamamoto, A., Kondo Y., Murao, R. "Cooling-Air Injection Into Secondary Flow and Loss Fields Within a Linear Turbine Cascade." TRANS. ASME. J. of Turbomachinery, Vol. 113, P. 375, 1991. 
16- Haller, B. R. and Camus, J. J., "Aerodynamic Loss Penalty Produced by Film Cooling Transonic Turbine Blades." TRANS. ASME. J. Engineering for Gas Turbine and Power, Vol. 106, P. 198, 1984.

17- Abdalla, H. A., Bassiouny, M. K., Sabry, T. I., and Abdel-Baky, M. A., "Cooling Effects on Boundary Layer Growth and Heat transfer in Gas Turbine Blading Cascade." Alexandria Engineering Journal, Faculty of Engineering, Alexandria University- Egypt, Vol., 38, P. 1, 1999.

18- Masaru, H., Nobuhide, K. and Masaya K, "Studies of Full- Coverage Film Cooling," Heat Transfer in Energy Problems, Hemisphere Publishing Corporation, 1983.

19- Schlichting, H., "Boundary Layer Theory," McGraw Hill Book Company New York, 1968.

20- Squire, H. B. and Winter, K. G., "The Secondary Flow in a Cascade of Airfoils in Non-Uniform Stream." J. of Aeronaut. Sci. Vol. 18, P. 271, 1951.

21 - Hawthorne, W. R., "Secondary Circulation in Fluid Flow," Proc. Roy. Soc. A., Vol. 206, P. 374, 1951.

22- Hawthorne, W. R., "Secondary Vorticity in Stratified Compressible Fluids in Rotating Systems," CUED/A-Turbo/ TR 63, Univ. of Cambridge, England, 1974.

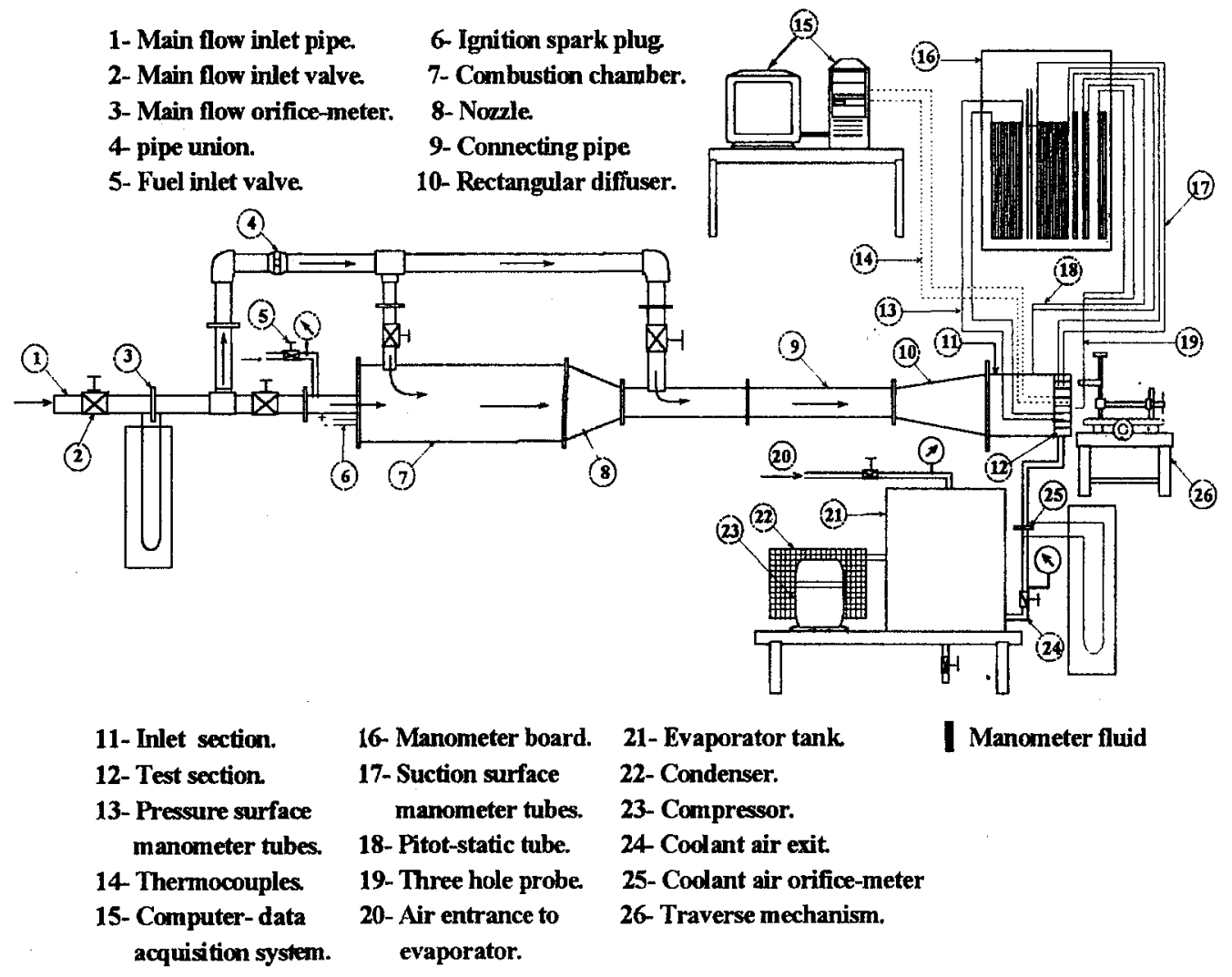

Fig. 1 Schematic layout of the apparatus 


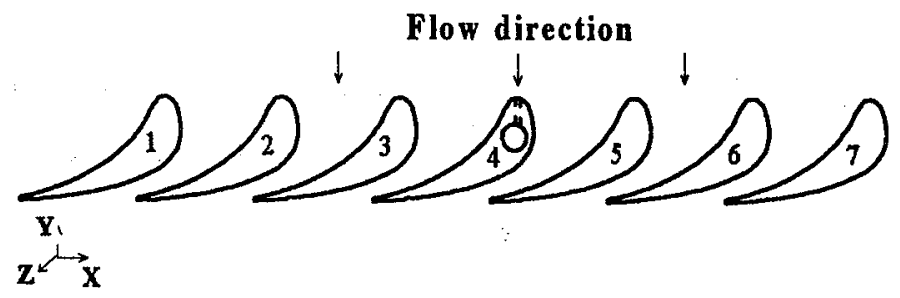

Fig. 2 cascade arrangement
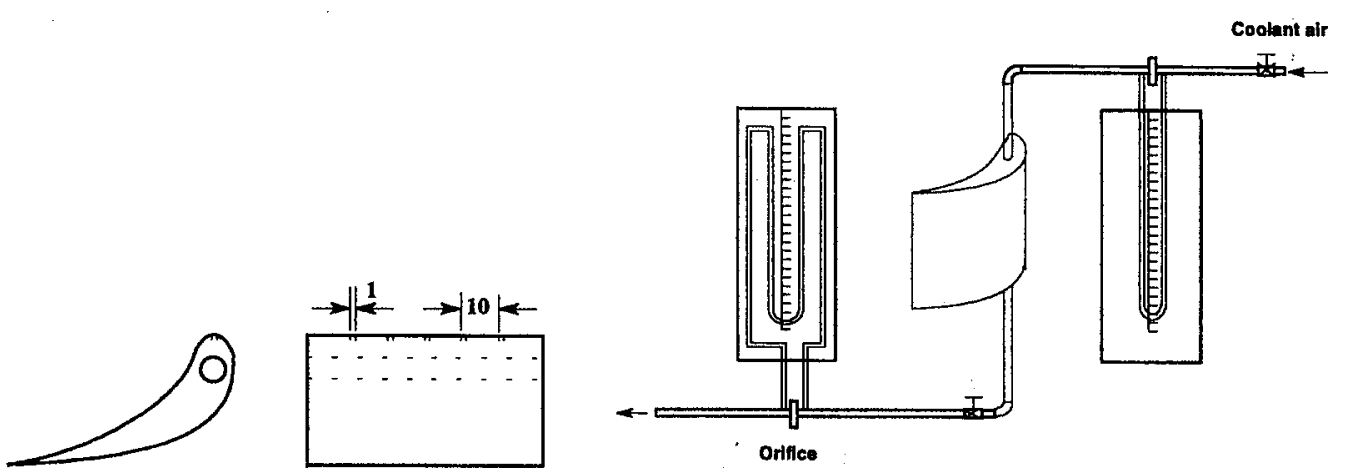

Fig. 3 Combined cooling Arrangement

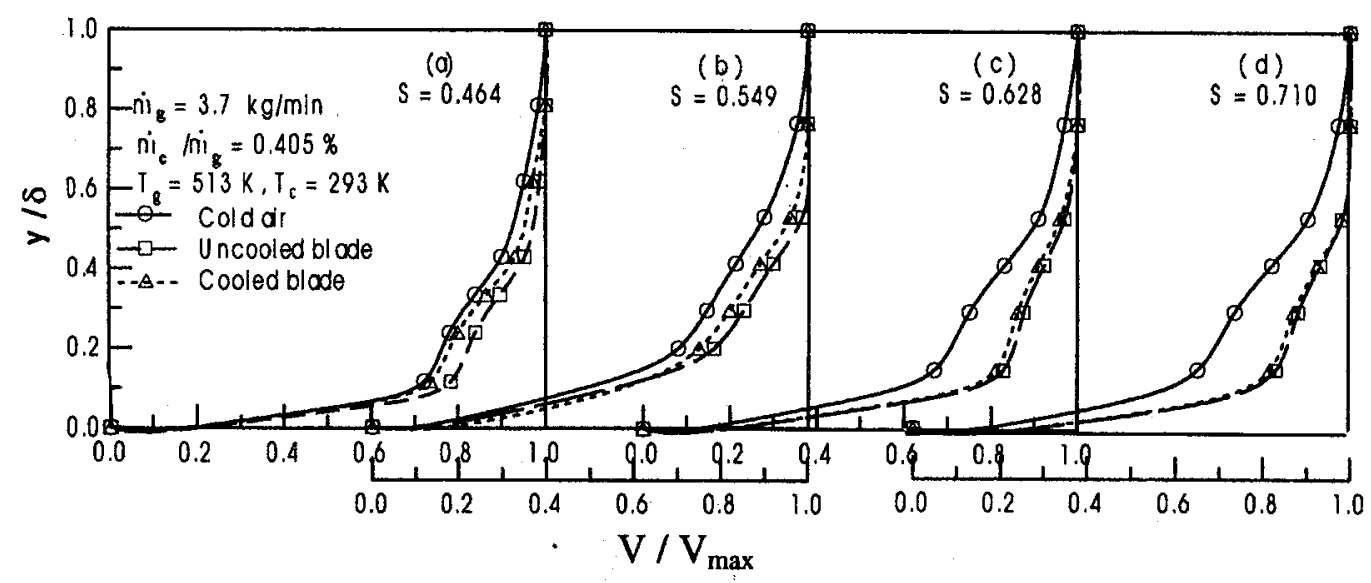

Fig. 4 Effect of cooling on mean velocity profiles on suction surface
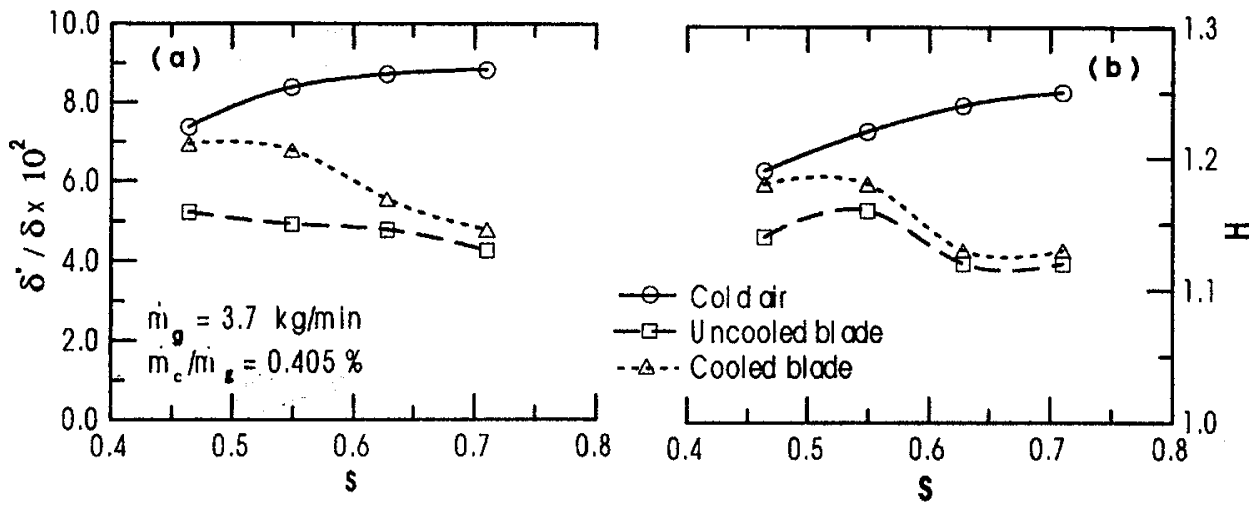

(a) Displacement thickness $\left(\delta^{*} / \delta\right)$

(b) Shape factor ( $\mathrm{H}$ )

Fig. 5 Effect of cooling on the boundary layer parameters 


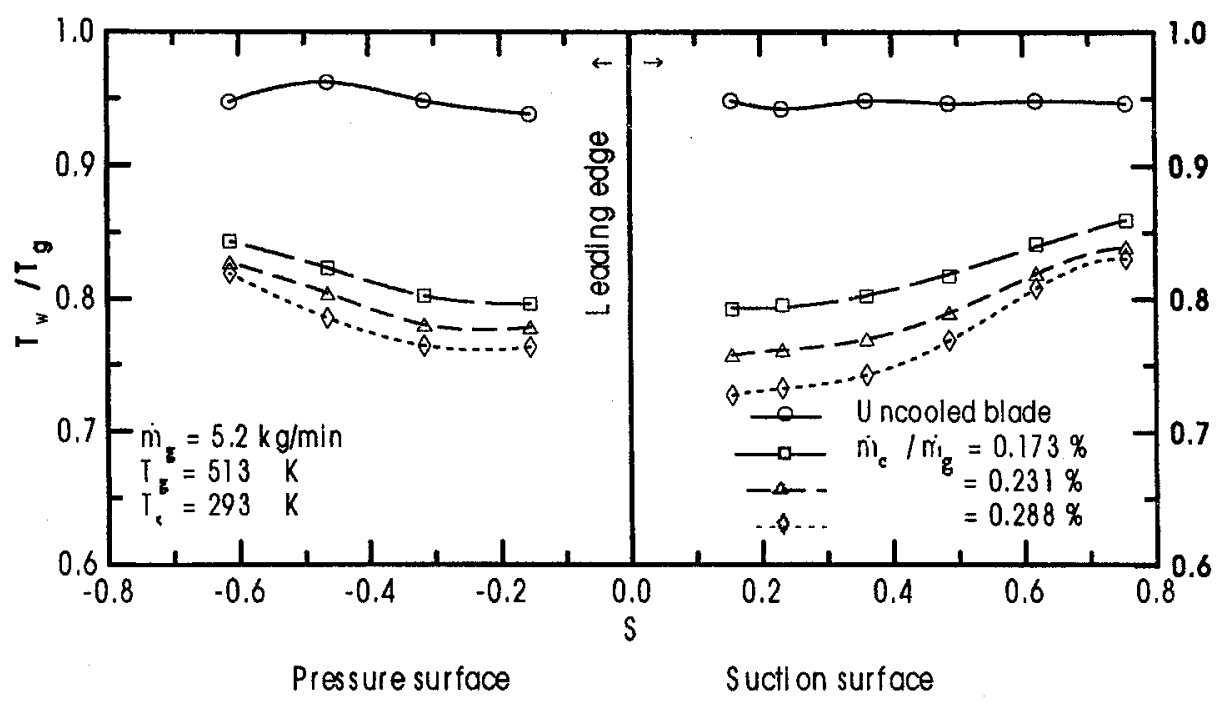

Fig. 6 Effect of coolant mass flow rate on the wall temperature ratio

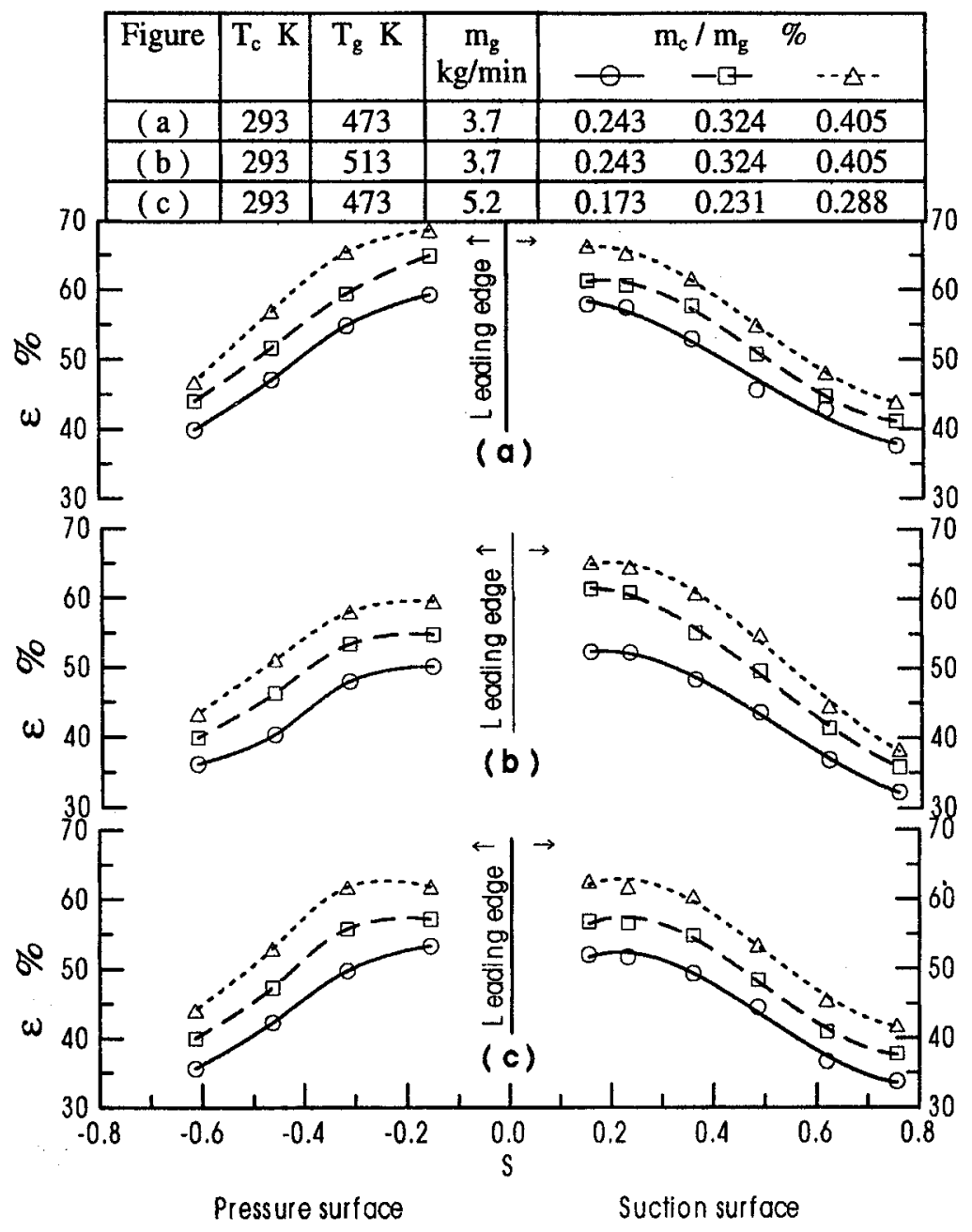

Fig. 7 Variation of blade cooling effectiveness along the blade surfaces 


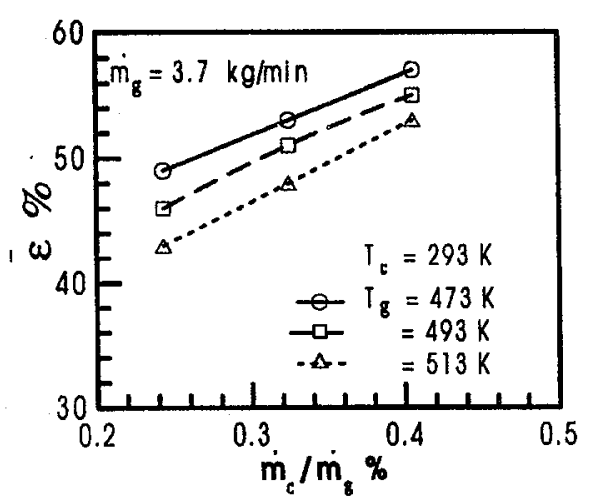

Fig. 8 Effect of cooling on the mean cooling effectiveness

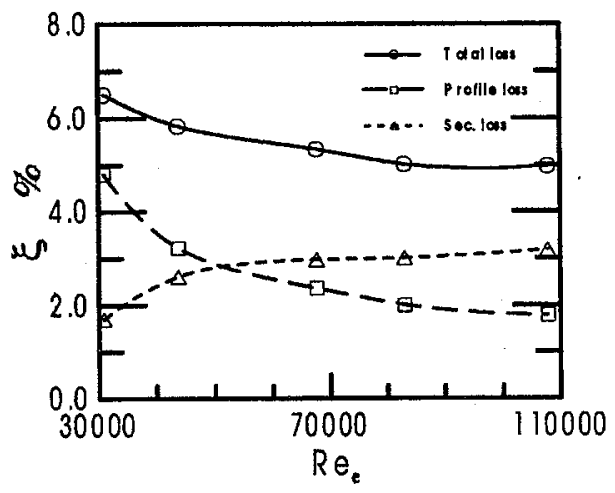

Fig. 10 Effect of Reynolds number on the cascade losses for cold air

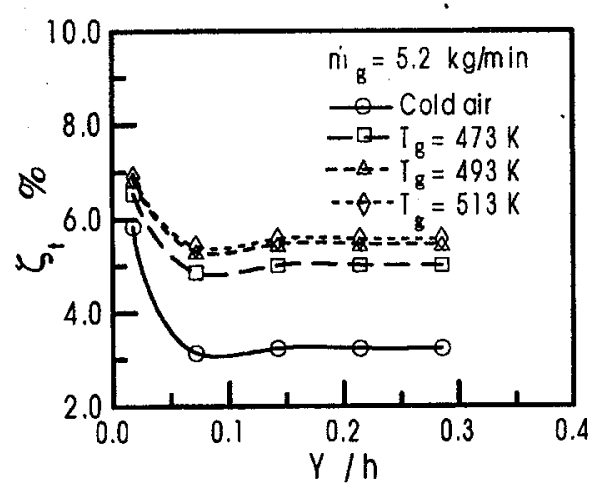

Fig. 12 Variation of aerodynamic loss coefficient of the cascade for hot gases

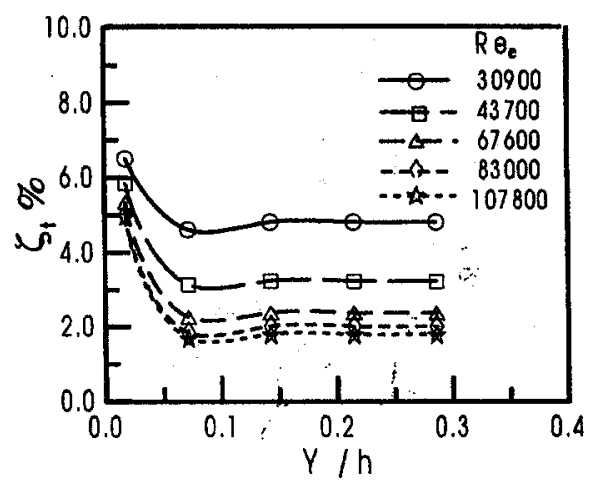

Fig. 9.Total aerodynamic loss for the cascade for cold air

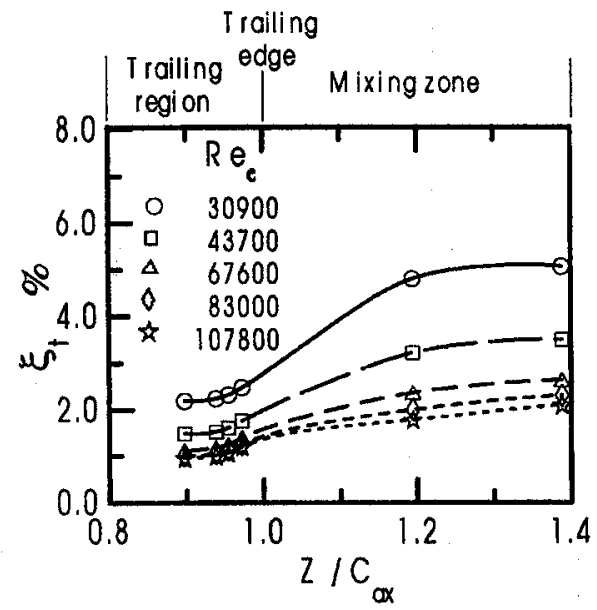

Fig. 11 Axial variation of the total aerodynamic loss coefficient downstream of the cascade

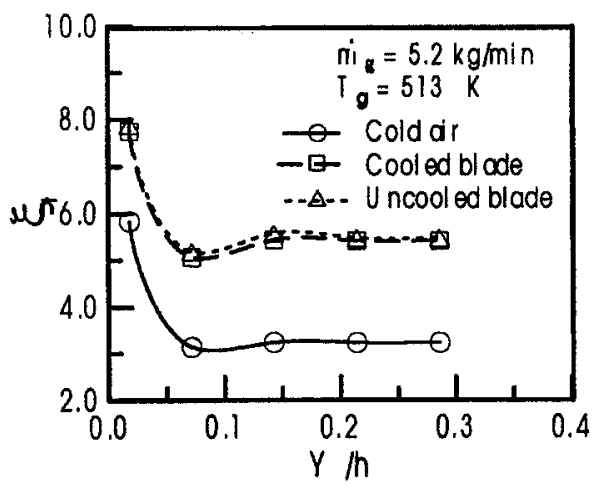

Fig. 13 Effect of cooling on the aerodynamic loss coefficient 

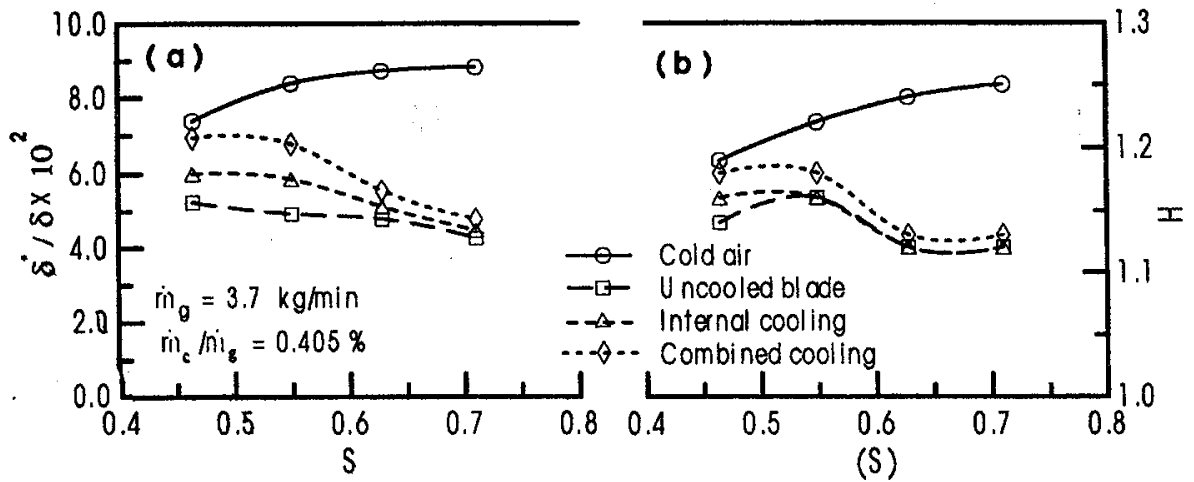

Fig. 14 Comparison between the effect of combined cooling and internal cooling on the boundary layer parameters

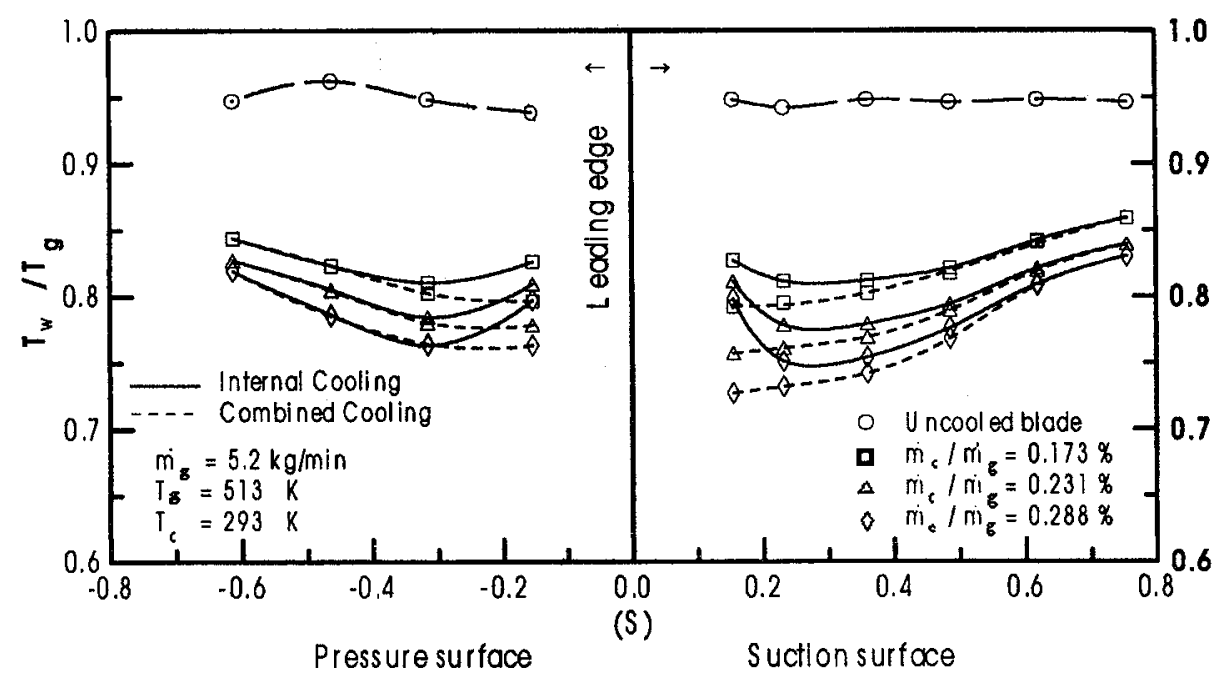

Fig. 15 Comparison between the effect of combined cooling and internal cooling on the wall temperature ratio

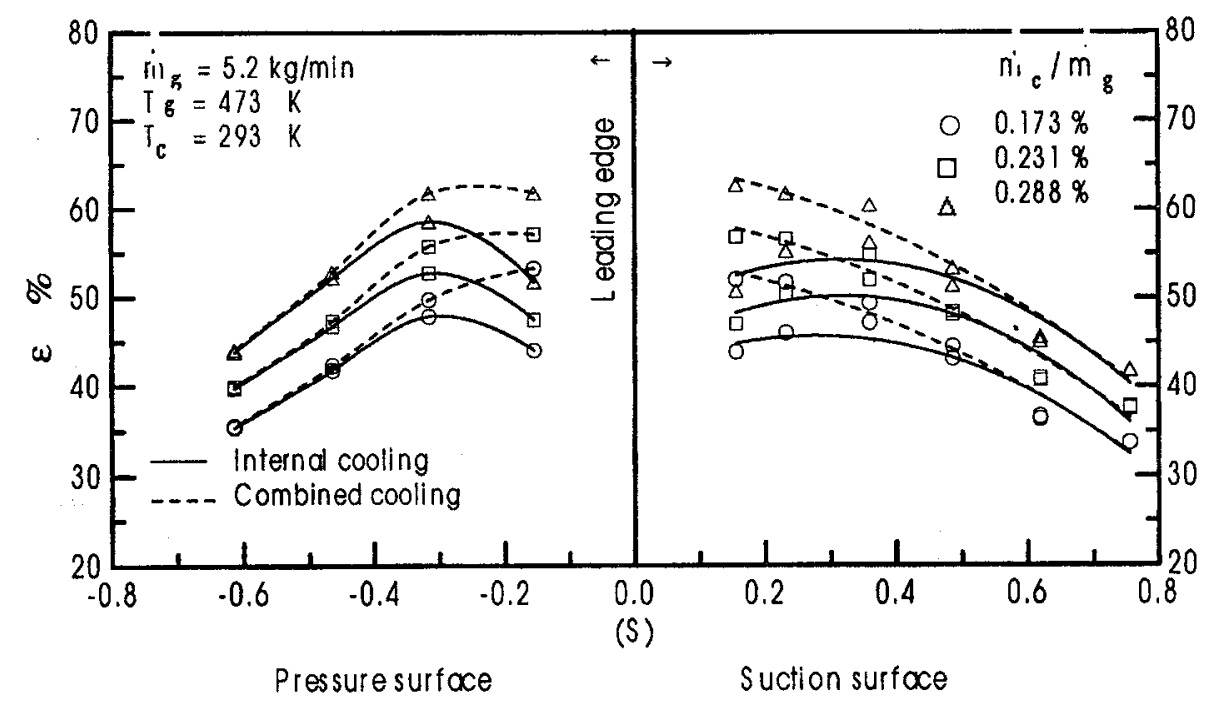

Fig. 16 Comparison between the effect of combined cooling and internal cooling on the cooling effectiveness. 


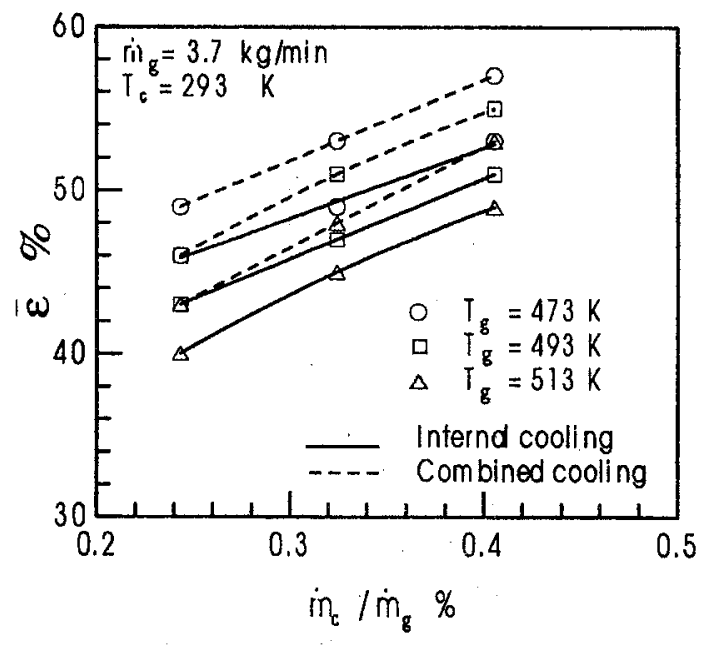

Fig. 17 Comparison between the effect of combined cooling and internal cooling on the mean cooling effectiveness. 


\section{بحث تأثير التبريد المزدوج على ريش الثربينات الغازية}

د. حسن عوض عبد الله ، د. محمد خليل بسيونى ، أ.د. طاهر إير اهيم صبرى

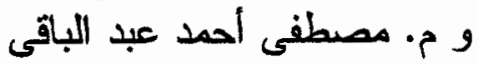

قسم هنسة القرى الميكانيكية - كلية الهنسة - جامعة المنوفية

\section{ملخص البحث}

في هذا البحث تم دراسة تأثير التبريد المزدوج (التثبريد الداخلي و التبريد السـطهي)

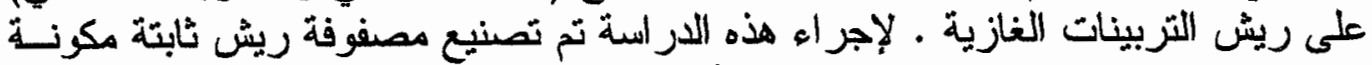

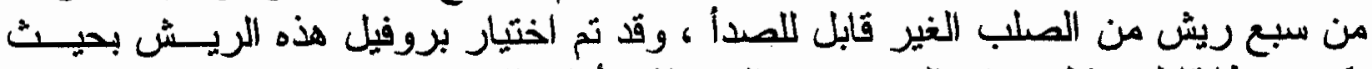

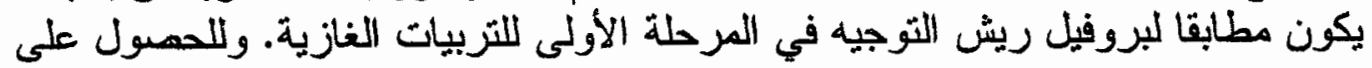

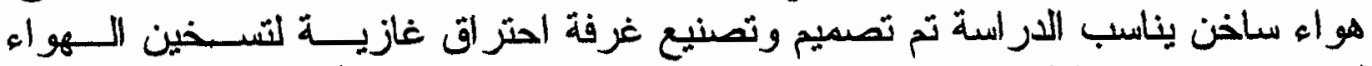

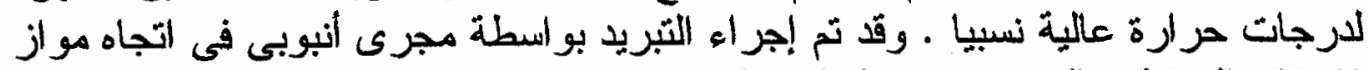

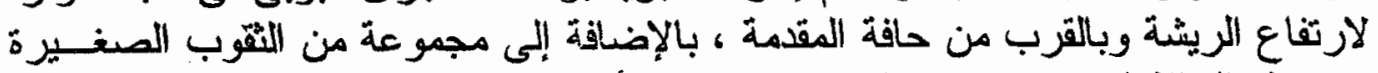

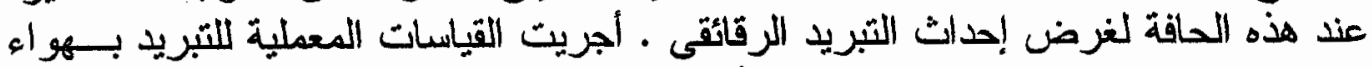

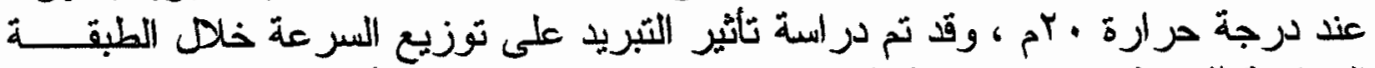

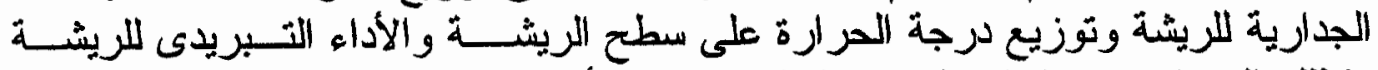

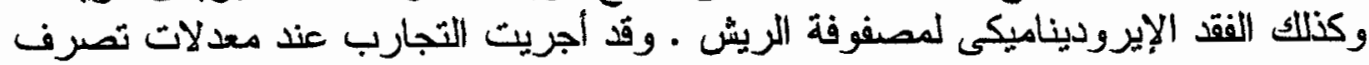

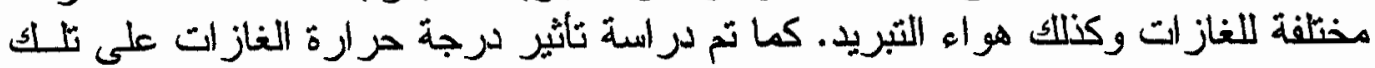

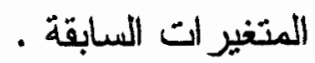

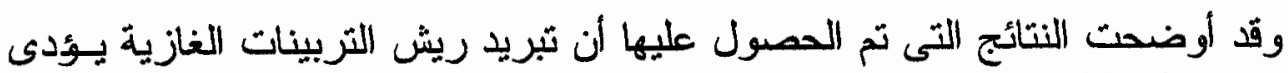

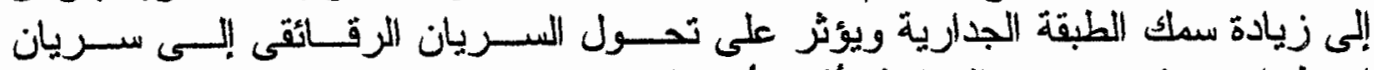

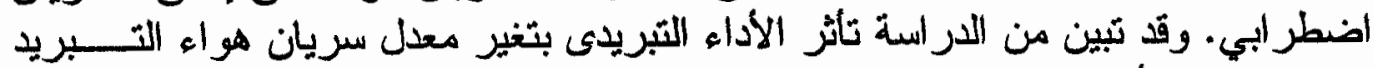

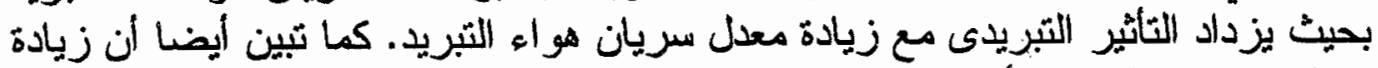

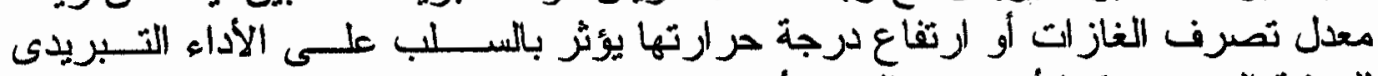

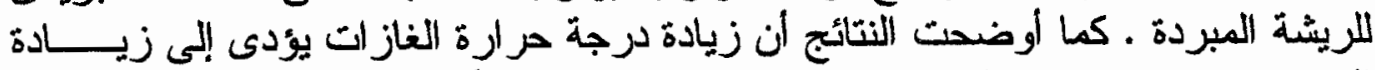

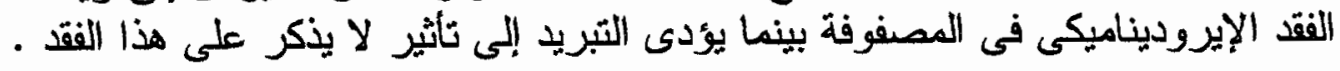

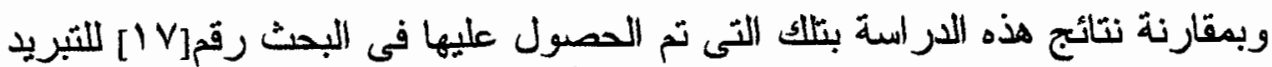

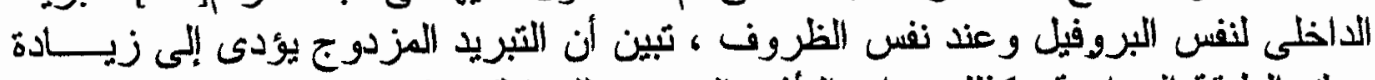

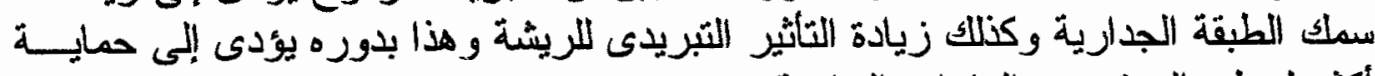
أكثر لسطح الريش من الغاز ات الساخنة . 